\title{
CFD Analysis of Unmanned Aerial Vehicles (UAV) Moving in Flocks
}

\author{
M. AtmacA*, B. Çetin And E. Yilmaz \\ Marmara University, Mechanical Engineering Department, Istanbul, Turkey
}

\begin{abstract}
In recent years, the use of unmanned aerial vehicles has increased rapidly. These vehicles have instant detection, tracking and destruction capabilities in military operations. In addition, when compared other conventional aerial vehicles, in the case of the vehicles down, any loss of driver life can be accounted for the most important factor in the view of widespread use of this vehicle. It is very important to make aerodynamic analyzes of unmanned aerial vehicles swarming behavior and to identify reliable zones for vehicles. It should be determined at what speeds and closeness of the flying vehicles along the specified routes the vehicles should be located within the frame. In this study, the models of an unmanned aerial vehicle and propellers of an UAV were designed with computational fluid dynamics. Especially turbulence, pressure, and speed changes have been investigated. Moreover, the range of interaction distance that they can create on each other is determined and reliable regions are determined.
\end{abstract}

DOI: 10.12693/APhysPolA.135.694

PACS/topics: swarm, UAV, drone, quadrotor, quadcopter, CFD, Fluent

\section{Introduction}

Unmanned aerial vehicles (UAV) are getting very popular on commercial, military and academic platforms. In the literature, there are some studies related to this topic [1-4]. Military applications currently represent the biggest part of the unmanned flying vehicle market, and this industrial sector is growing strongly [5]. During the last fourthly years UAVs have been modernized with developing technology and have become common vehicles that can be used in many places with many designs and features [6-8]. Although, when UAVs moves together, some unwanted problems can be created in the sense that each UAV creates aerodynamic force zone which affects other UAV's motion. In this study, flow characteristics of unmanned aerial vehicles moving together was investigated using existing computational fluid dynamics (CFD) tools.

\section{Numerical methodology}

The FLUENT, which is a commercial program, is used to analyze the flow in the numerical model. Finite volume method was used to discretize the governing equations. CFD processes are divided into three main parts, solver and post-processing parts. In this study, $k-\varepsilon$ turbulence model was used when considering the literature studies. Details about the simulations are given in Table I. In this numerical study, moving (sliding) mesh and moving reference frame model were used in the mathematical algorithm since moving simulations were done. Stationary and moving reference frames are shown in Fig. 1.

* corresponding author; e-mail: matmaca@marmara.edu.tr

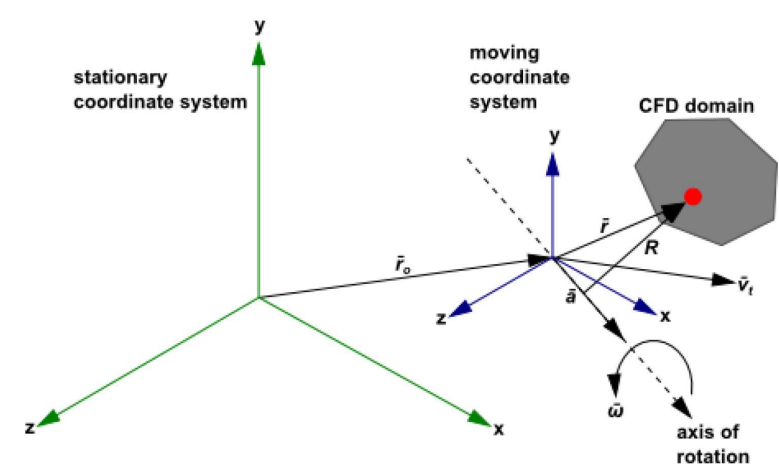

Fig. 1. Stationary and moving reference frames [9].

Simulation details

TABLE I

\begin{tabular}{l|l}
\hline \hline Program & Ansys v18.2 \\
\hline size function & proximity and curvature \\
\hline nodes & 6466439 \\
\hline elements & 4682211 \\
\hline \multicolumn{2}{c}{ Fluent } \\
\hline space & 3 D \\
\hline time & unsteady, 2nd-order implicit \\
\hline viscous & realizable $k$-epsilon \\
\hline wall treatment & turbulence model \\
\hline mesh motion & standard wall functions \\
\hline $\begin{array}{l}\text { moving mesh } \\
\text { rotation speed [rpm] }\end{array}$ & \pm 10000 \\
\hline material & air (fluid) \\
\hline time step [s] & 0.01 \\
\hline max. iterations per time step & 200 \\
\hline \multicolumn{2}{c}{ Pressure--velocity coupling } \\
\hline type & simple \\
\hline $\begin{array}{l}\text { pressure } \\
\text { turbulent kinetic energy, } \\
\text { turbulent dissipation rate }\end{array}$ & upwind \\
\hline
\end{tabular}


The parameters in Fig. 1 are related by the following equations:

$$
\begin{aligned}
& \boldsymbol{\omega}=\omega \hat{\boldsymbol{a}}, \\
& \boldsymbol{v}_{r}=\boldsymbol{v}-\boldsymbol{u}_{r}, \\
& \boldsymbol{u}_{r}=\boldsymbol{v}_{t}+\boldsymbol{\omega} \times \boldsymbol{r},
\end{aligned}
$$

where $\hat{\boldsymbol{a}}$ is axis of rotation, $\boldsymbol{v}_{r}$ is relative velocity, $\boldsymbol{v}$ is absolute velocity, $\boldsymbol{u}_{r}$ is velocity of moving reference frame, $\boldsymbol{v}_{t}$ is translational velocity of frame, $\boldsymbol{\omega}$ is angular velocity; $\boldsymbol{\omega}$ and $\boldsymbol{v}_{t}$ are time functions.

\section{Results and discussion}

Detailed mesh images of drone as a UAV are shown in Fig. 2a and b. Figure $2 \mathrm{c}$ and $\mathrm{d}$ shows the velocity streamline and volume rendering velocity that occur after $2 \mathrm{~s}$, respectively.

In this analysis, $1 \mathrm{~m}$ distance was taken between two drones along $y$-axis, as shown in Fig. 2e. The middle point of the top of the drone was chosen as a reference point. Distance between axis of propellers from corner to corner is $250 \mathrm{~mm}$. Line locations are shown in Fig. 2e.

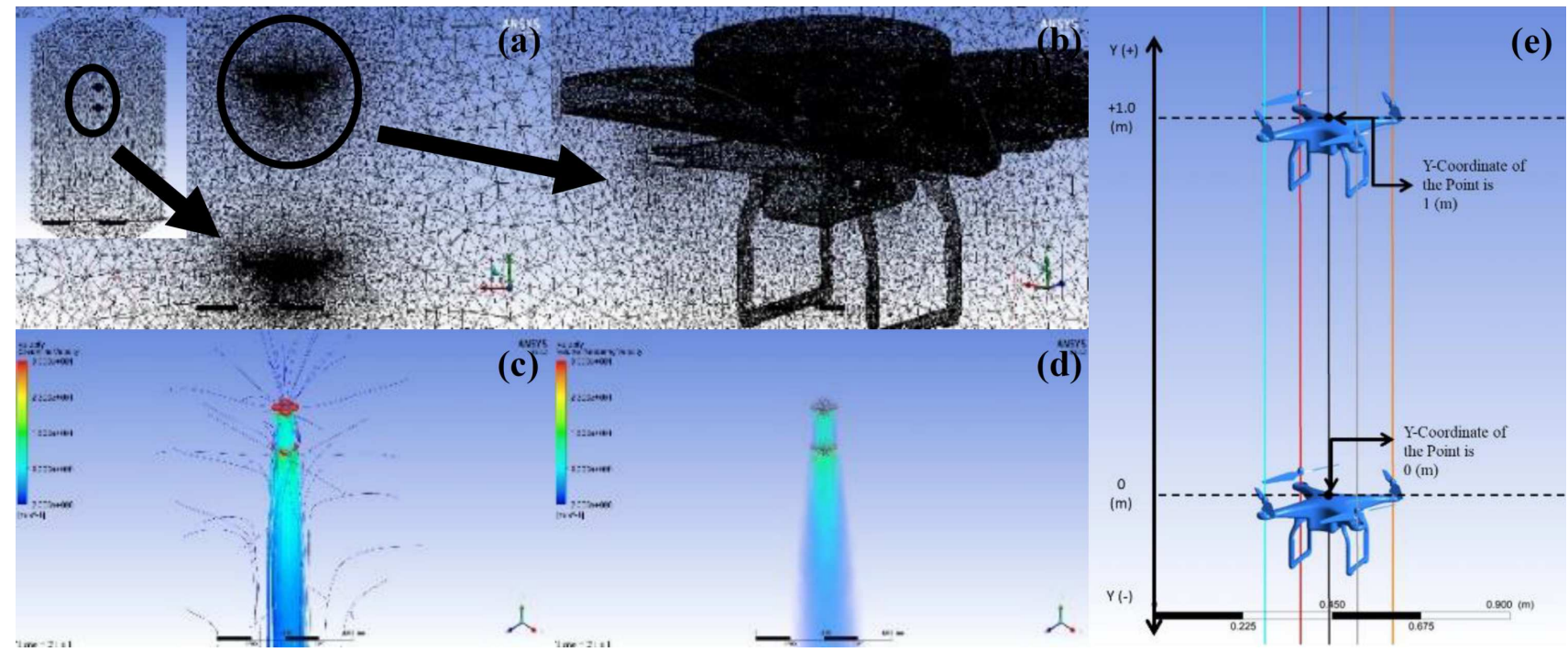

Fig. 2. (a), (b) Mesh images of drone, (c) streamline velocity, (d) volume rendering velocity, (e) line locations.
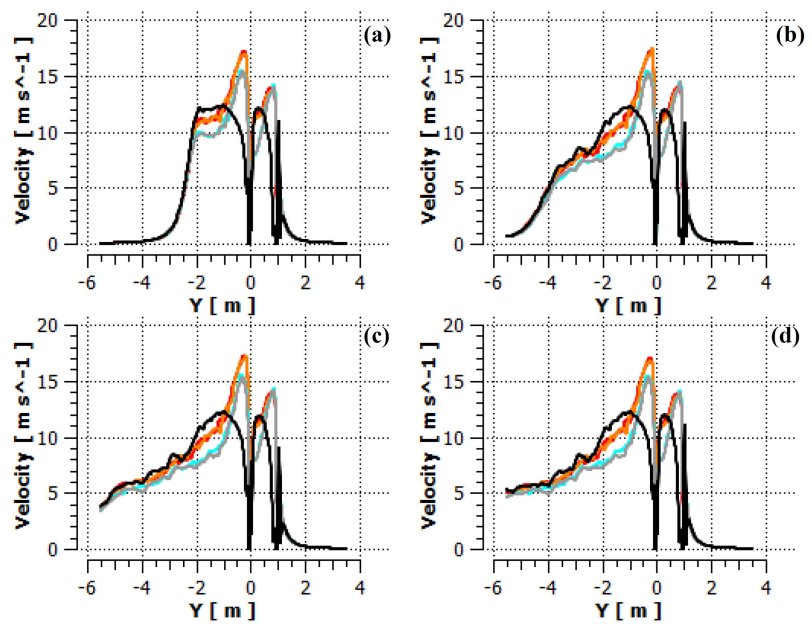

Fig. 3. Velocity distributions: (a) time $=0.5 \mathrm{~s}$, (b) time $=1 \mathrm{~s}$, (c) time $=1.5 \mathrm{~s}$, (d) time $=2 \mathrm{~s}$.

Figure $3 \mathrm{a}-\mathrm{d}$ shows time-dependent velocity distributions according to $y$-axis $(-6 \mathrm{~m}$ to $4 \mathrm{~m})$. As can be seen in Fig. 3, first drone creates velocity of approximately $14 \mathrm{~m} / \mathrm{s}$ at all axes of propellers. Second drone rear propellers (red and orange) create velocity of approximately
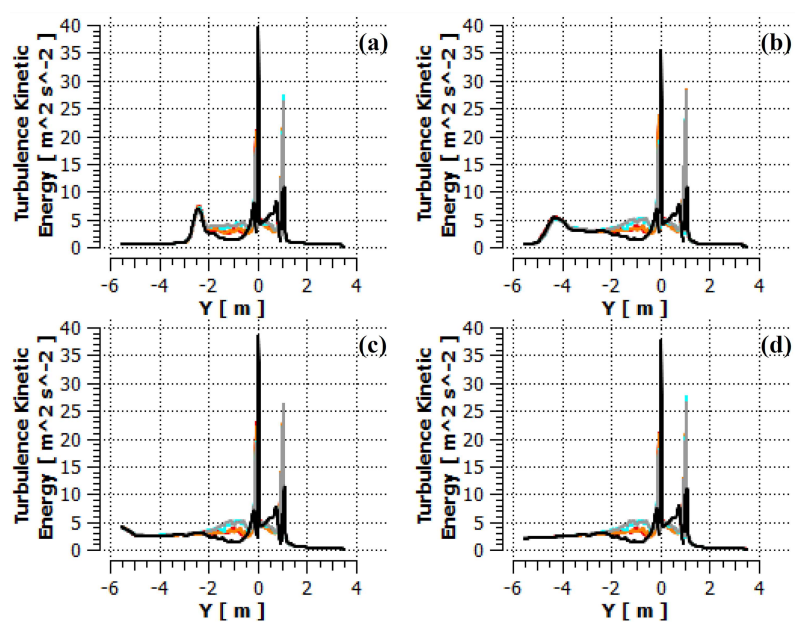

Fig. 4. Turbulence kinetic energy distributions: (a) time $=0.5 \mathrm{~s}$, (b) time $=1 \mathrm{~s}$, (c) time $=1.5 \mathrm{~s}$, (d) time $=2 \mathrm{~s}$.

$17 \mathrm{~m} / \mathrm{s}$ as front propellers (blue and grey) create velocity of $15 \mathrm{~m} / \mathrm{s}$. This means second drone is affected by air condition resulted from first drone movement causing unstable motion in second drone. 
Figure $4 \mathrm{a}-\mathrm{d}$ shows time-dependent turbulence kinetic energy distributions according to $y$-axis. Looking at Fig. 4, if we inspect graphics along time intervals, it can be seen that the appearing turbulence kinetic energy between -4 and $-2 \mathrm{~m}$ is getting stabilized by time.
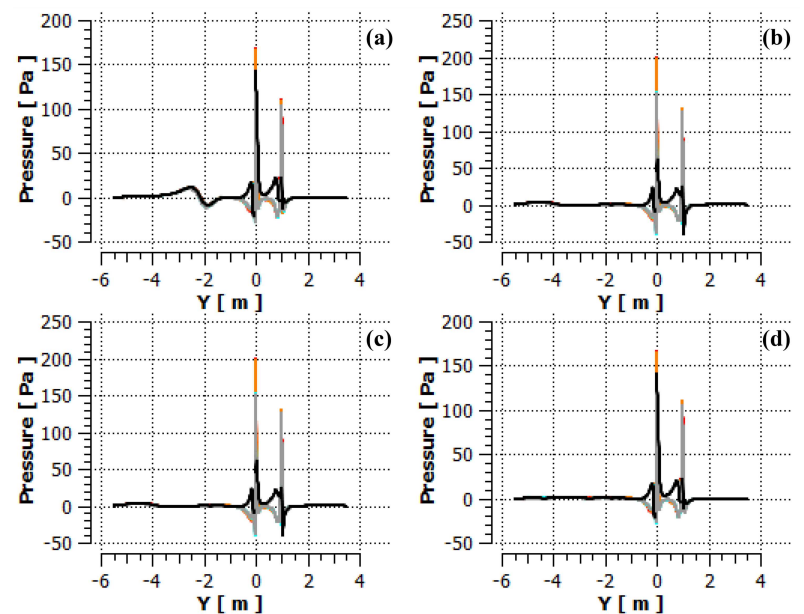

Fig. 5. Pressure distributions: (a) time $=0.5 \mathrm{~s}$, (b) time $=1 \mathrm{~s}$, (c) time $=1.5 \mathrm{~s}$, (d) time $=2 \mathrm{~s}$.

In Fig. 5a-d when we take into consideration axis of the drone-midpoint, the considerable pressure force applied from first drone to second drone can be seen easily. This force makes second drone move downward.

\section{Conclusion}

In this research we understood that the drones moving as flocks affect their mutual movement. Hence the drones moving very close should have a certain fly distance to minimize aerodynamic effects. For this reason, UAVs working autonomously should be detected by itself and be able to control the distance from other UAVs. Therefore, each autonomous UAV model should be redesigned to define aerodynamically own safe-zone.

\section{References}

[1] T.F. Villa, F. Gonzalez, B. Miljievic, Z.D. Ristovski, L. Morawska, Sensors 16, 2016.

[2] N.D. Divitiis, J. Aircraft 40, 759 (2003).

[3] K. Herrick, Air Space Europe 2, 25 (2000).

[4] F.G. Harmon, A.A. Frank, J.J. Chattot, J. Aircraft 43, 1490 (2006).

[5] I.C. Dikmen, A. Arisoy, H. Temeltas, in: Proc. 4th Int. Conf. on Recent Advances in Space Technologies, 2009, p. 722.

[6] R. Austin, Unmanned Aircraft Systems: UAVS Design, Development and Deployment, Wiley, Hoboken (NJ) 2010.

[7] K. Nonami, F. Kendoul, S. Suzuki, W. Wang, D. Nakazawa, Autonomous Flying Robots - Unmanned Aerial Vehicles and Micro Aerial Vehicles, Springer, Japan 2010.

[8] F.A.T. Al-Saedi, R.A. Sabar,IJCSET 5, 190 (2015).

[9] ANSYS ${ }^{\circledR}$, Release 17, Help System, Fluent Theory Guide, ANSYS, Inc. 